CASE REPORTS

\title{
Exchange transfusion in the treatment of Russell's viper bite
}

\author{
O. A. PEIRIS \\ M.D., M.R.C.P., M.R.C.P.E. \\ Senior Lecturer in Medicine, \\ University of Ceylon, Colombo
}

K. D. P. Wimalaratne

M.B.B.S. (Cey.)

Research Assistant to

Professor of Medicine

\author{
A. Nimalasuriya \\ M.B.B.S. (Cey.) \\ House Officer to \\ Professor of Medicine
}

\section{Department of Medicine, University of Colombo}

This report deals with a case of severe toxaemia resulting from a Russell's viper bite treated by means of an exchange transfusion. We believe that this is a very satisfactory, although untried, procedure in the treatment of this condition.

\section{Case report}

G.T., a 22-year-old male student was bitten by a Russell's viper at about 08.00 hours on 30 August 1968. He was admitted to a local hospital $3 \mathrm{hr}$ after the bite. Within $1 \mathrm{hr}$ of admission he showed all signs of severe toxaemia, as evidenced by pain and swelling in the region of the bite, frank haemoglobinuria and characteristic neurological signs. He was admitted under our care at the General Hospital, Colombo, at 12.15 hours on 31 August 1968 (17 hr after the bite). He was confused, the pulse rate was $110 / \mathrm{min}$, the blood pressure was $90 / 60 \mathrm{mmHg}$. He was pale and jaundiced. Two fang-marks were seen about 1 in. above the tip of the left medial malleolus and the area around this was swollen, warm and tender. He had bilateral ptosis and complete external ophthalmoplegia. His speech was slurred and there was dysphagia. Respiration was shallow and diaphragmatic. He had flaccid paresis of all four limbs and the deep reflexes were all absent.

\section{Treatment}

The wound had been incised and a venous torniquet had been applied soon after the bite. Fifty millilitres of polyvalent antivenin had been given at the local hospital about $3 \mathrm{hr}$ after the bite. Ampicillin $500 \mathrm{mg}$ i.m. 6-hourly and hydrocortisone $100 \mathrm{mg}$ i.v. 4-hourly were commenced after he came under our care. ATS, 1500 units, and $1 \mathrm{ml}$ of tetanus toxoid were given. Three hundred and fifty millilitres of $20 \%$ mannitol was given and this resulted in a diuresis of $300 \mathrm{ml}$ within $3 \mathrm{hr}$. A further infusion of mannitol $(350 \mathrm{ml})$ was repeated $4 \mathrm{hr}$ after the first. Intravenous fluid therapy was continued with $5 \%$ dextrose.

There was an obvious deterioration in his condition in spite of the above measures. Twenty-eight hours after the bite the pallor had increased, the pulse rate was $130 / \mathrm{min}$ and the blood pressure had dropped to $75 / 50 \mathrm{mmHg}$. The haemoglobinuria had increased. Mental confusion worsened, there was complete dysphagia and complete paralysis of all four limbs and very shallow breathing. The blood examined at this stage showed warm haemolysins, increased free haemoglobin in the plasma and an increased serum bilirubin (see Table 1).

An exchange transfusion was commenced at this stage using fresh Group $A \mathrm{Rh}+$ blood. One and a half litres of blood were exchanged in the first $2 \mathrm{hr}$ and this resulted in a remarkable improvement in his condition. The blood pressure increased to $100 / 80$ $\mathrm{mmHg}$, the pulse rate was $90 / \mathrm{min}$ and the pallor was much less. Most dramatic of all was the reversal of the neurotoxaemia; he became much clearer in mind and went to the extent of recalling the moment he was bitten with great accuracy. Ptosis, slurring of speech and dysphagia showed a marked improvement and it was no longer necessary to use the electric sucker to remove secretions from his throat. He was able to move his limbs and his respiration became normal. A specimen of blood taken at this time showed no evidence of haemolysins. A further 1.8 litres of blood were exchanged during the next $3 \mathrm{hr}$. 


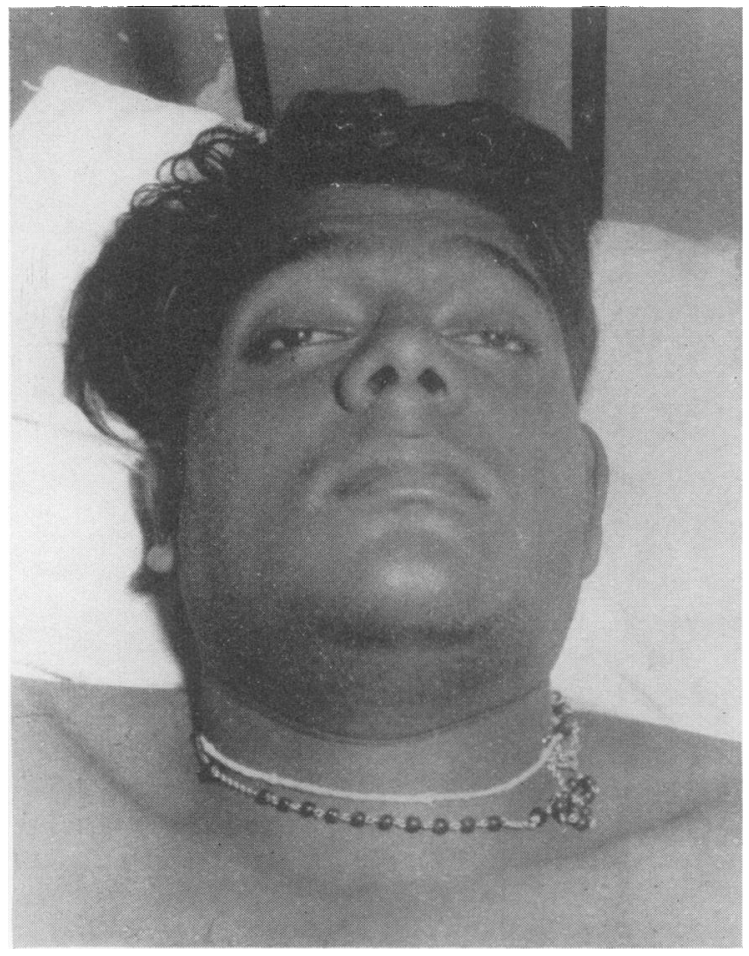

Fig. 1. Bilateral ptosis and complete ophthalmoplegia $28 \mathrm{hr}$ after the bite (before exchange transfusion).

Twenty per cent mannitol $(700 \mathrm{ml})$ and 1 litre of $5 \%$ dextrose were given during the 24-hr period following the exchange transfusion. He made an uneventful recovery and was able to walk on the 3rd day after the transfusion.

\section{Discussion}

Apart from the administration of polyvalent antivenin (at least $100 \mathrm{ml}$ ) soon after the bite (Reid, 1968), no significant therapy has been described for the treatment of Russell's viper bite. The case illustrated here shows the great value of exchange transfusion even at a very advanced state of toxaemia (28 $\mathrm{hr}$ after the bite). The rapid reversal of the effects of the neurotoxin particularly on the respiratory and pharyngeal muscles was dramatic. In spite of the rapid and massive haemolysis no further complications occurred. Severe renal failure, which in our experience has a very protracted course in these cases, did not occur. We believe that the high mortality associated with snake bite may be significantly reduced by the use of exchange transfusion as treatment.

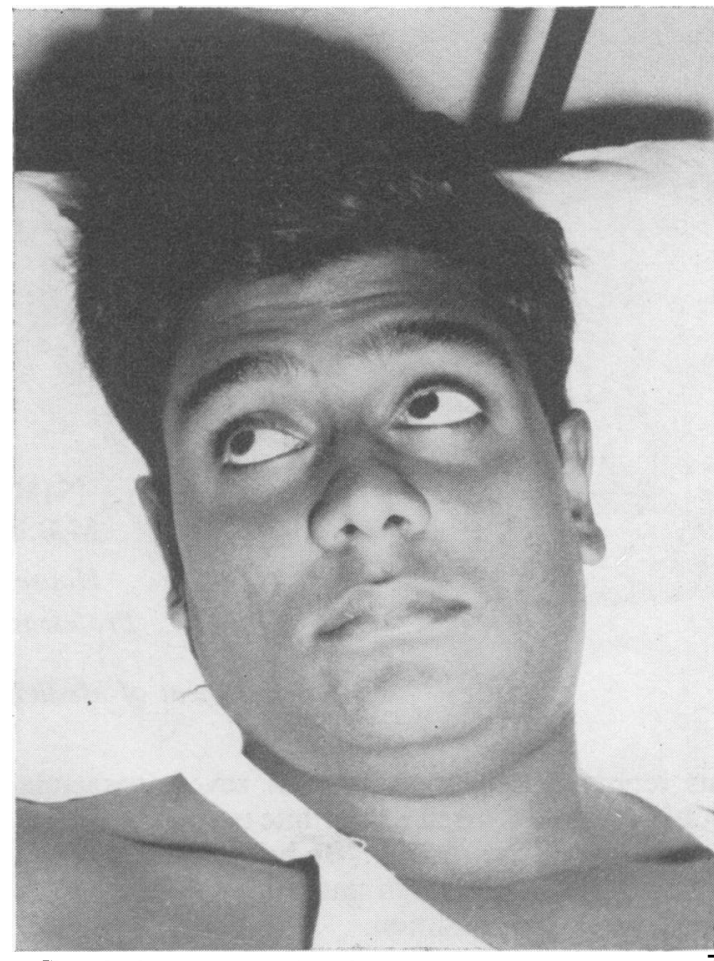

FIG. 2. Recovery $48 \mathrm{hr}$ after exchange transfusion.

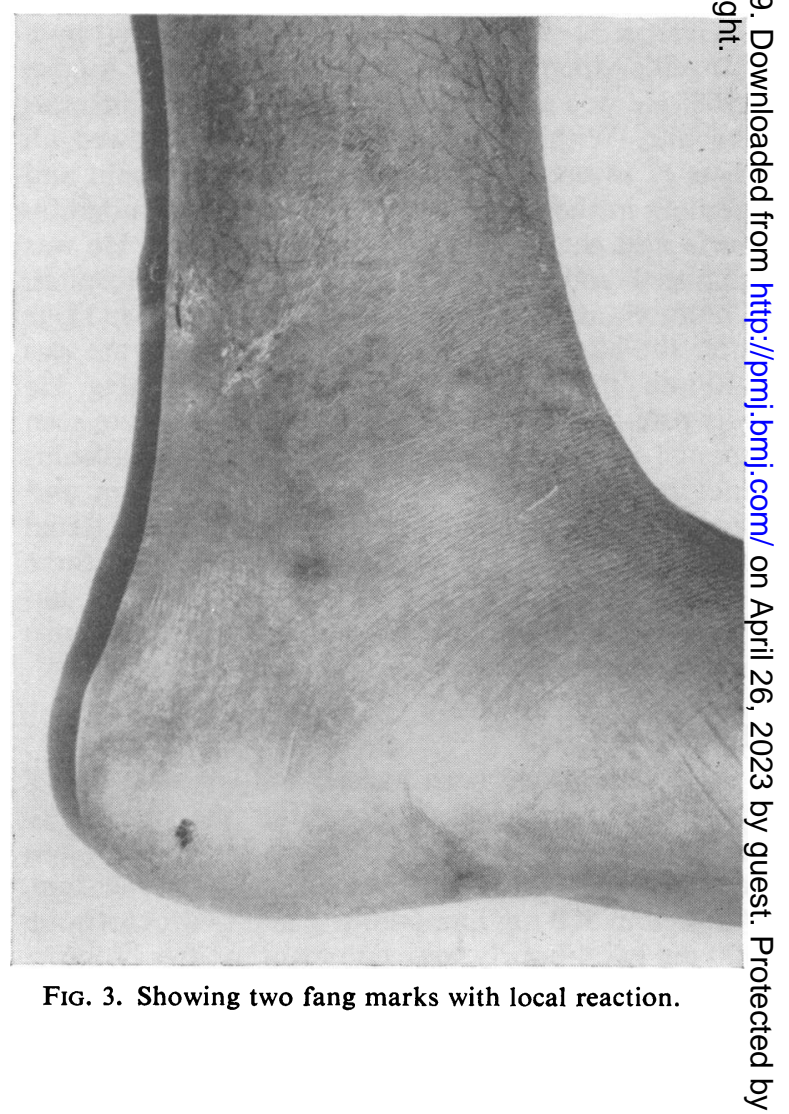


TABLE 1

\begin{tabular}{|c|c|c|c|c|}
\hline & \multirow{2}{*}{$\begin{array}{c}\text { Before } \\
\text { transfusion }\end{array}$} & \multicolumn{3}{|c|}{ After transfusion } \\
\hline & & $24 \mathrm{hr}$ & $72 \mathrm{hr}$ & 6 days \\
\hline Haemoglobin (g) & ND & $7 \cdot 5$ & $7 \cdot 6$ & $7 \cdot 6$ \\
\hline PCV & 20 & 29 & 23 & 29 \\
\hline Plasma free $\mathrm{Hb}(\mathrm{mg} / 100 \mathrm{ml})$ & 241 & 141 & 5 & 6 \\
\hline Bleeding time & 14 & 6 & 4 & 1 \\
\hline Clotting time & No clot & 8 & 5.5 & 2 \\
\hline Haemolysins & $3+$ & \pm & - & - \\
\hline Serum bilirubin $(\mathrm{mg} / 100 \mathrm{ml})$ & 4.0 & $4 \cdot 8$ & $1 \cdot 3$ & 0.6 \\
\hline Urine volume $/ 24 \mathrm{hr}(\mathrm{ml})$ & 970 & 1750 & 1500 & 1300 \\
\hline Haemoglobinuria & $4+$ & $1+$ & - & - \\
\hline Urobilin & $2+$ & $3+$ & $3+$ & $1+$ \\
\hline Blood urea $(\mathrm{mg} / 100 \mathrm{ml})$ & 30 & 148 & 75 & 32 \\
\hline Serum $\mathrm{Na}(\mathrm{mEq} / \mathrm{l})$ & & & 136 & 140 \\
\hline Serum $\mathrm{K}(\mathrm{mEq} / \mathrm{l})$ & 3.8 & $4 \cdot 2$ & $4 \cdot 6$ & $4 \cdot 6$ \\
\hline Serum $\mathrm{HCO}_{3}(\mathrm{mEq} / \mathrm{l})$ & $21 \cdot 2$ & $27 \cdot 6$ & $28 \cdot 4$ & $30 \cdot 0$ \\
\hline SGOT Frankel Units & ND & 110 & 84 & 36 \\
\hline SGPT Frankel Units & & 94 & 96 & 68 \\
\hline
\end{tabular}

\section{Acknowledgment}

We are greatly indebted to Dr P. E. Gunawardena, Superintendent of the National Blood Transfusion Service for his help in this case.

\section{Reference}

ReID, H.A. (1968) Snake bite in the tropics. Brit. med. J. 3, 359.

\section{Congenital Heinz-body haemolytic anaemia due to Haemoglobin Hammersmith}

\author{
N. K. SHINTON \\ M.D., M.R.C.P., M.C.Path.
}

\author{
D. C. Thursby-Pelham \\ M.D., M.R.C.P., D.C.H.
}

\section{H. PARRY Williams \\ M.R.C.S., F.R.C.P.}

\section{Coventry and Warwickshire Hospital and City General Hospital, Stoke-on-Trent}

THE ASSOCIATION of haemolytic anaemia with red cell inclusion bodies was well recognized at the end of the Nineteenth Century in workers exposed to coal tar derivatives (Heinz, 1890a, b) and following potassium chlorate poisoning (Reiss, 1882). Since then a variety of drugs and chemicals have been shown to induce the formation of these so called Heinz bodies in large numbers (Dacie, 1967). Small numbers are seen after splenectomy for any cause (Webster, 1949). A child was described by Cathie (1952) who had undergone splenectomy for a congenital haemolytic anaemia and who had a persistently high frequency of red cell Heinz bodies and who had not been exposed to a toxic agent likely to be responsible for the phenomena. A similar case reported by Lange \& Ackeroyd (1958) was later

* Requests for reprints should be sent to Dr N. K. Shinton. shown by Zinkham \& Lenhard (1959) to be associated with an hereditary deficiency of the red cell enzyme glucose-6-phosphate dehydrogenase. Anomalies in haemoglobin electrophoresis were noted in cases of congenital Heinz body haemolytic anaemia by Schmid, Brecher \& Clemens (1959) and by Scott et al. (1960) without the nature being identified. The association with an identifiable haemoglobin anomaly-Haemoglobin Zurich, was reported by Frick, Hitzig \& Betke (1962). Haemolytic episodes here followed the ingestion of sulphonamides. Spontaneous haemolysis with Heinz body formation was later described in association with other abnormal haemoglobins-Haemoglobin Köln (Pribilla, 1962), Haemoglobin Ube-I (Shibata et al., 1963), Haemoglobin Gallier Genova (Sansome \& Pic, 1965), Haemoglobin Seattle (Huehns, 1965) and 